\title{
Storability of paprika varieties measured by non-destructive acoustic method
}

\author{
Muha V. ${ }^{1}$, Istella S. ${ }^{2}$ and Tompos D. ${ }^{2}$ \\ ${ }^{I}$ Corvinus University of Budapest, Faculty of Food Science, Department of Physics-Control \\ ${ }^{2}$ Corvinus University of Budapest, Faculty of Horticulture Science, \\ Department of Vegetable and Mushroom Growing
}

\begin{abstract}
Summary: During our experiments, the storability of paprika (Capsicum annuum) samples was measured by a non-destructive acoustic method. The aims of our work were the determination of the applicability and reproducibility of the acoustic stiffness method for paprika, the investigation of the optimum measuring conditions. In order to compare the main paprika varieties regarding shelf-life, our further aim was to follow the softening phenomenon or textural changes (i.e. changes in stiffness) of different paprika varieties measured by the nondestructive acoustic stiffness method. Five different varieties of paprika grown in hydroponics growing system were used for the measurements. All paprika varieties were stored at $20^{\circ} \mathrm{C}$ for two weeks. Samples were tested on every $2^{\text {nd }}$ or $3^{\text {rd }}$ day. The acoustic method was found to be suitable to follow the softening of paprika samples. The characteristic frequency of the acoustic signal could be well detected and clearly separated from the other vibration peaks. Tapping the top of the paprika was observed to give a clearer and less noisy signal compared to the signal obtained by tapping the sample's shoulder. The acoustic results showed the same tendencies with regard to softening during storage as the impact method showed in our previous experiments.
\end{abstract}

Key words: non-destructive method, paprika, firmness, acoustic, shelf-life, storability, softening, quality

\section{Introduction}

Hungarian-type sweet pepper plays an important role in the domestic vegetable market. (Zsom et al., 2003) So nowadays the importance of paprika is increasing rapidly, together with consumers' demand for long shelf-life and excellent overall quality (Balázs et al., 2003). Nutrients are very important mainly for hydroponics. The quality of a product depends on many factors. One of them is the $\mathrm{N} / \mathrm{K}$ ratio that has a definite effect on the yield quantity and quality. This problem was measured and analysed at the Corvinus University of Budapest (Szepesi et al., 2003). In our experiment the same fertilization method was used for tested varieties.

Horticultural commodities continue their life-processes and survive for a long time after harvest. (Zsom \& Balla 2004) The main goal for storage is the maintenance of initial product quality until it reaches the consumer. One of the main consumer preference factors for paprika is firmness or texture. In order to fulfil this requirement, the selection of varieties with good overall quality and long shelf-life, together with optimal storage conditions, plays a major role.

Quick and objective non-destructive stiffness measuring methods are becoming more and more important. So, a nondestructive physical method (dynamic acoustic stiffness measurement method) was used for stiffness measurements during our experiments. This method is suitable for following changes in stiffness (softening) sensitively, and objectively.
The sound of the tapped sample gives relevant information about the overall stiffness of the product. Usually the acoustic method is applied to spherical shape, roughly homogeneous and solid samples (Fekete \& Felföldi, 2002). Because of the unique structure and shape of paprika, the acoustic stiffness method was not previously applied for this horticultural product.

The aims of our work were the determination of the applicability and reproducibility of the acoustic stiffness method for paprika and the investigation of the optimum measuring conditions. In order to compare the main paprika varieties regarding shelf-life, our further aim was to follow the softening phenomenon or textural changes (i.e. changes in stiffness) of different paprika varieties measured by the non-destructive acoustic stiffness method.

\section{Materials and methods}

Five paprika varieties (Danubia, Hó, HRF, Kaméleon and Kárpia), grown on rock wool were used for tests. The experiments were carried out at the beginning of October 2003 and the paprika samples were stored at $20^{\circ} \mathrm{C}$ for 12 days. Sample firmness was measured by the acoustic method every second or third day. The mass loss was also calculated from the electric balance measured sample mass. Since the measurement was non-destructive, it was repeated on the same samples during the experiments. 
A non-destructive (acoustic) measuring method was used for texture measurement of paprika samples. According to our opinion, the acoustic method gives relevant information about the overall stiffness of the sample while the impact method characterizes only the firmness of the sample surface (Fekete \& Felföldi 2000).

\section{Acoustic method}

The paprika was tapped lightly with a wooden stick and a microphone located under the cushioning sample holder sensed the paprika's acoustic response. (Figure 1) The microphone's output was recorded by the sound card of a computer. The Custom Fast Fourier Transform software is used to analyze the recorded acoustic response. There is a significant relationship between the peak (characteristic) frequency of the acoustic signal and the sample's firmness (Felföldi, 1996). The characteristic frequency and the sample mass are used to calculate the firmness coefficient:

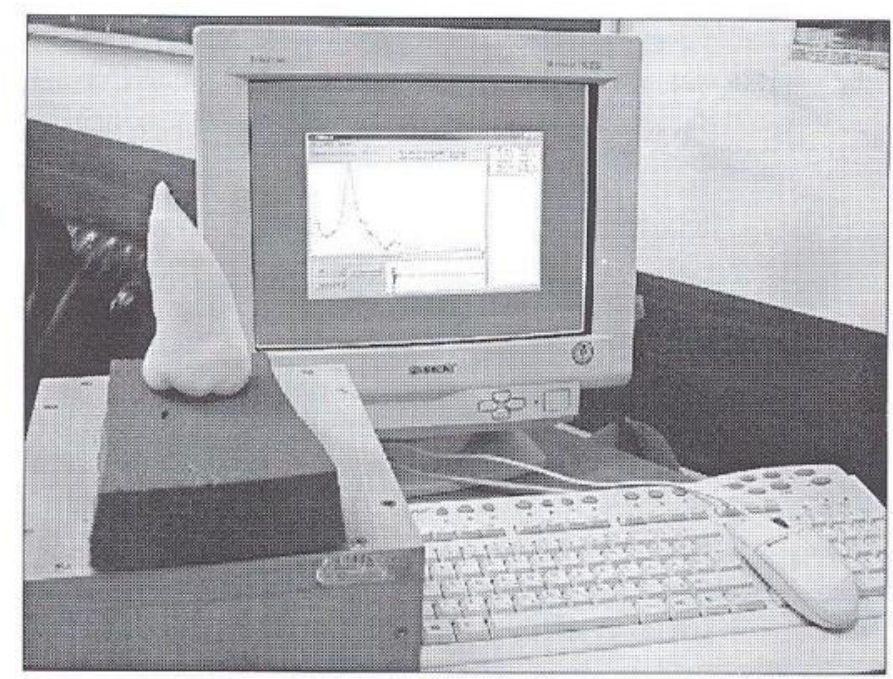

Figure 1 Arrangement of the acoustic stiffness method

\section{$S=f^{2 *} m * 10^{-6}[\mathrm{~N} / \mathrm{mm}]$,}

where $\mathrm{S}=$ acoustic firmness coefficient

$\mathrm{f}=$ characteristic frequency of the sample $(\mathrm{Hz})$

$\mathrm{m}=$ sample mass $(\mathrm{g})$

Paprika samples were tapped at two different points, top and shoulder, at each experiment.

The data for both experiments proved normal distributions. For the evaluation of the data and for the comparison of the varieties, the ANOVA method was used. Significant differences were evaluated at the $95 \%$ significance level. The SPSS $^{\mathrm{TM}}$ program was used for statistical evaluation.

\section{Results and discussion}

Data from the acoustic stiffness method showed excellent repeatability. The $f^{2 *} \mathrm{~m}$ relation that is normally applied for spherical, roughly homogeneous, solid samples was found to be applicable for firmness measurements in the case of paprika. The acoustic measuring method gave relevant information about changes in firmness during storage at $20^{\circ} \mathrm{C}$. The characteristic frequency of the acoustic signal obtained by this method could be well detected and clearly separated from the other vibration peaks. Tapping the top of the paprika was observed to give a clearer and less noisy signal (Figure 3 ) compared to the signal obtained by tapping the sample's shoulder (Figure 4).

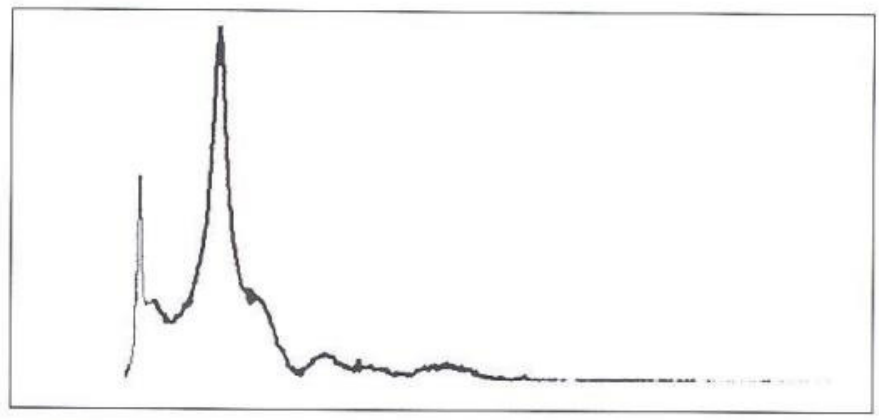

Figure 3 The acoustic signal when tapping the top of the paprika

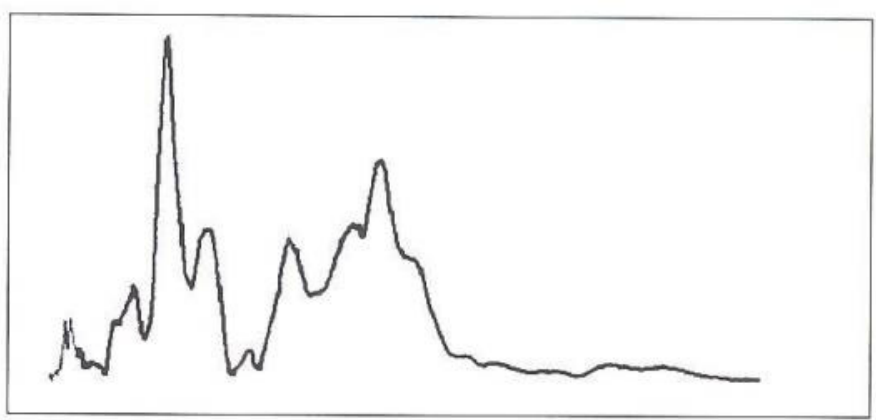

Figure 4 The acoustic signal when tapping the shoulder of the paprika

No significant differences were found between the results of tapping the paprika on the top or on the shoulder. In the case of paprika, the measured signal from the top is easier to detect than the signal from the shoulder.

\section{Results of the storage experiment}

Figure 5 shows the changes in the acoustic signal of paprika varieties during storage. The following could be observed:

- the character of the spectra and the behavior of the resonant frequency is similar during the experiment,

- the resonant frequency of the sample decreases monotonically,

- this decreasing shows the softening of the samples.

All paprika varieties in our experiment showed the above tendency.

According to the firmness experiments, Kárpia $F_{1}$ variety was found to be the hardest while Hó $\mathrm{F}_{1}$ variety was the softest at harvest (the first day of measurement) (Figures 6-7). Significant differences (at 95\% significance level) were found between the change in the firmness of 


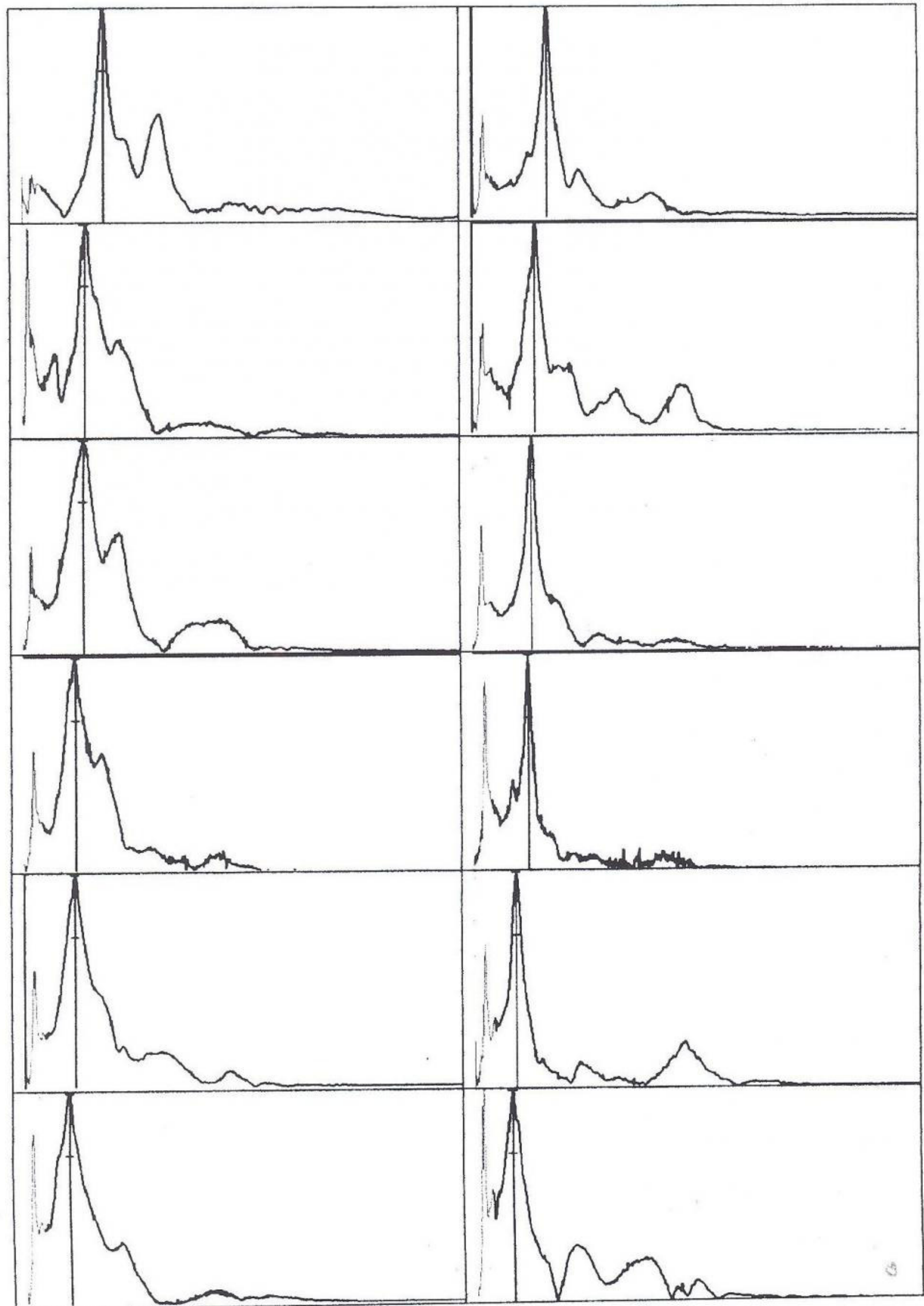

a) top signal of Kaméleon $F_{1}$

b) top signal of Danubia $F_{1}$

Figure 5 Changes in the acoustic signal of paprika during storage for different specimen 


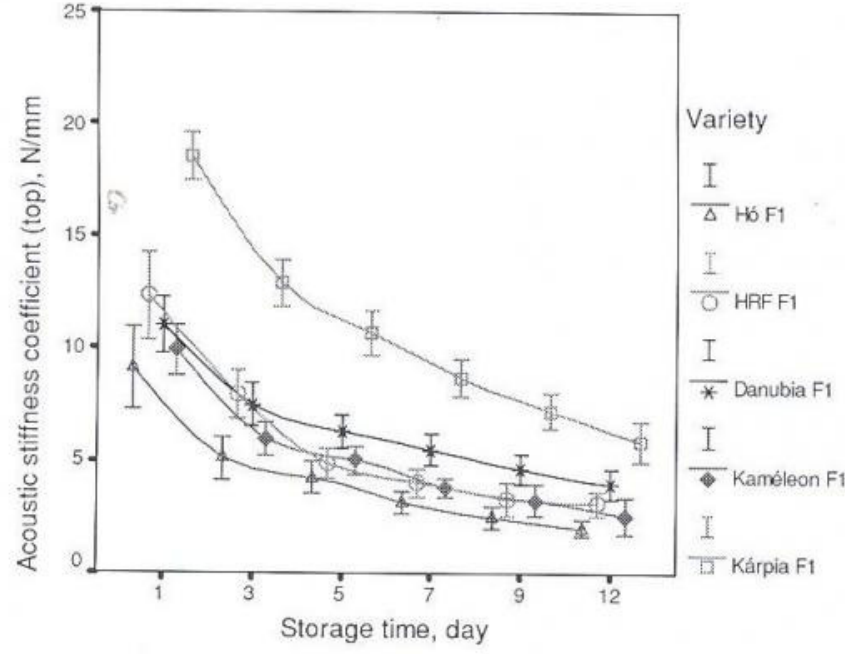

Figure 6 Changes in the acoustic stiffness coefficient of the paprika varieties measured at the top position versus storage time (average values with the standard deviations)

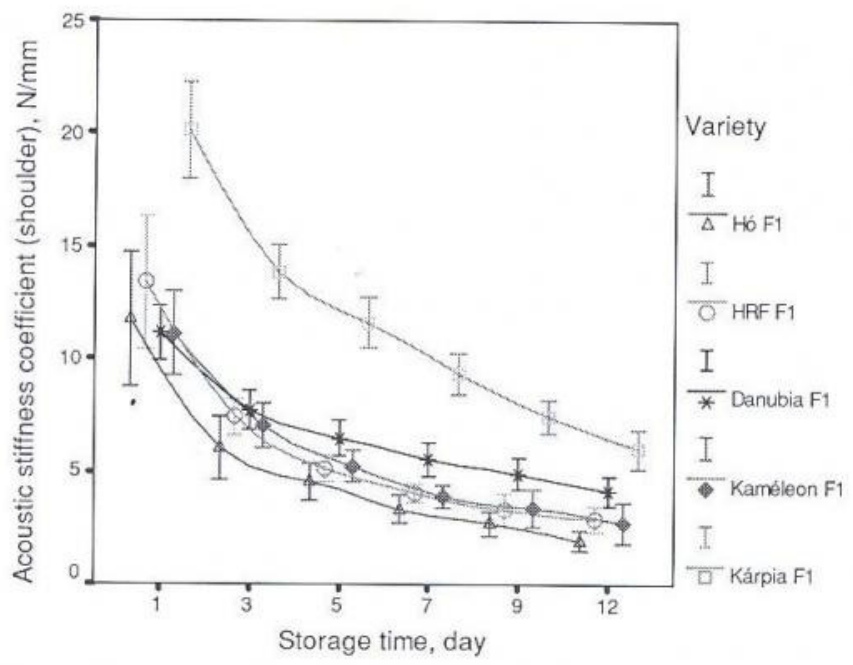

Figure 7 Changes in the acoustic stiffness coefficient measured at the shoulder of the paprika varieties versus storage time based on the results of the first test (average values with the standard deviations)

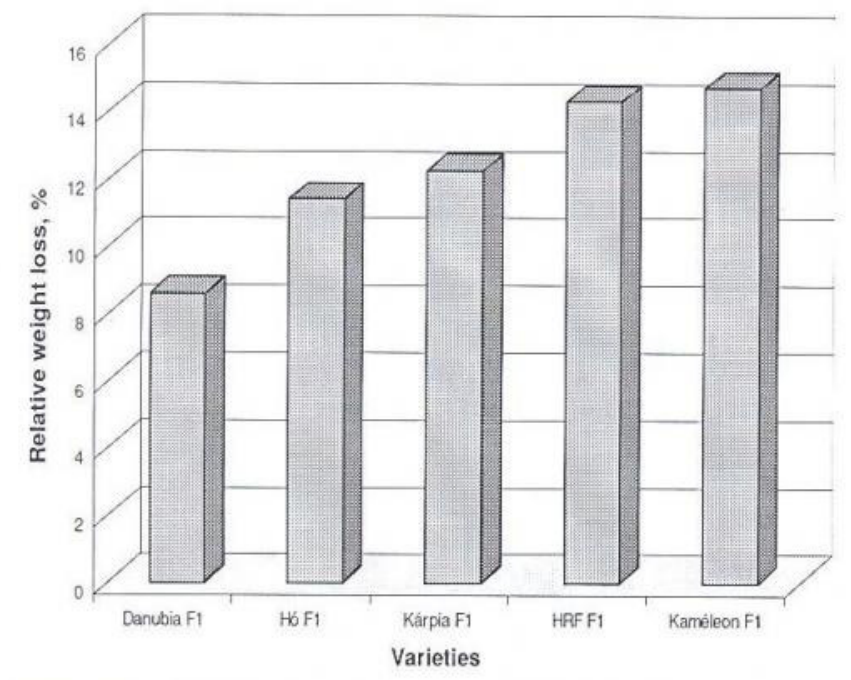

Figure 8 Relative weight loss of measured paprika varieties
Kárpia $F_{1}$ variety and that of the other varieties after the 5 th day. For white colored paprika varieties, the smallest firmness change was measured in the case of Danubia $F_{1}$. The changes in the textures of the other 3 varieties (Hó $\mathrm{F}_{1}$, HRF $F_{1}$, Kaméleon $F_{1}$ ) showed similar tendencies as for Kárpia $F_{1}$. More significant softening was observed after the 5 th day.

Hó $\mathrm{F}_{1}(11 \%)$ and Kárpia $\mathrm{F}_{1}(12 \%)$ lost about the same weight. Comparing this fact with the results of the measurement of the mechanical properties (where Kárpia $F_{1}$ was found to be the hardest variety and Hó $F_{1}$ was the softest), we conclude that the acoustic method and the acoustic stiffness coefficient represent real hardness characteristics and it is suitable for measuring shelf-life.

Figure 8 shows the relative weight loss of varieties. Danubia $\mathrm{F}_{1}$ and Kaméleon $\mathrm{F}_{1}$ lost the smallest and highest amount of weight, respectively

\section{Conclusions}

After the determination of the correct acoustic measurement conditions, the acoustic method that was previously used mainly for spherical, roughly homogeneous, solid samples could be used for firmness measurements of paprika. The characteristic frequency obtained by the acoustic stiffness measurement method was found to be clearly recognized and highly reproducible. During the storage, the firmness changes could be followed by the acoustic method.

According to our experiments, Kárpia $\mathrm{F}_{1}$ variety is suggested for industrial use and export markets because of its thick epidermis and long shelf life. Hence, it is suitable for long-term transport and storage.

From the other varieties, Danubia $F_{1}$ was suggested for fresh market export due to its firmness and long shelf life. We recommend Kaméleon $\mathrm{F}_{1}$, Hó $\mathrm{F}_{1}$, and $\mathrm{HRF} \mathrm{F}_{1}$ varieties for the domestic markets, because of their better shape and higher average fruit weight.

\section{Acknowledgements}

This research was supported by the Hungarian Scientific Research Fund (OTKA T 046756 AG4).

\section{References}

Balázs S., Kristóf L., Terbe I. \& Zatykó F. (2003): Legfontosabb zöldségnövények mint hungarikumok. Kertgazdaság. 35(2): 75-83.

Fekete A. \& Felföldi J. (2000): Evaluation of fruit firmness. Hungarian Agricultural Engineering. 13: 53-56.

Fekete A. \& Felföldi J. (2002): Test methods for the Assessment of Tomato Ripening - Hungarian Agricultural Engineering. 15: $39-40$. 
Felföldi J. (1996): Firmness assessment of fruits and vegetables based on acoustic parameters. Journal of Food Physics. 58: 39-47.

Szepesi Zs., Tóth K. \& Terbe I. (2003): N:K ration and its effect on paprika yield and quality in hydroculture. International Journal of Horticultural Science. 9 (1): 35-38.

Zsom T. \& Balla Cs. (2002): Examination of post-harvest factors influencing the texture of Hungarian type sweet pepper during storage, Proceedings of the 5th International Conference on Food Physics, Brno, Czech Republic, May 30-June 1, 138-142.
Zsom T. \& Balla Cs. (2004): Respiratory activity of sweet pepper during post-harvest storage at chilling temperature and after mechanical loading. $2^{\text {nd }}$ Central European Congress on Food, Budapest, 26-28 April 2004, Book of Abstracts, 278.

Zsom T., Balla Cs. \& Merész P. (2003): Changes in the membrane permeability of Hungarian-type sweet pepper during maturation. Proceedings of the International Conference Postharvest Unlimited, Acta Horticulturae. 599: 513-518. 